\title{
USING DIGITAL BADGES TO PROMOTE PROFESSIONAL DEVELOPMENT IN HIGHER EDUCATION
}

\author{
Gary Janchenko, Robert Morris University, janchenko@rmu.edu \\ Anthony Rodi, D.Sc. University of Pittsburgh, afrodi@pitt.edu
}

\begin{abstract}
Micro-credentials or Digital Badges represent the result of acquiring a new skill or competency in a specific discipline. It is the digital collection of these skills that is recognized beyond the traditional degree that distinguishes the development of key skills that are valued in both industry settings and in higher education. The formal and informal acquisition of this knowledge has become a collection of digital credentials that become part of a learning network or ecosystem. The purpose of this paper is to explore the current ways that digital badging is being used to track the professional development of faculty, students, and staff and to explore other ways to use the badges in the future to promote better communication, learning and growth opportunities for employees. This paper explores the literature around micro-credentials and digital badges and the roles that these credentials play while moving into the future of open education. Also discussed are the challenges of collecting knowledge along with the balancing of the needs of traditional education with the trends of modern society.
\end{abstract}

Keywords: Digital Badges, Micro-Credentials, Open Badges, Higher Education, Knowledge, Knowledge Management

\section{INTRODUCTION}

Institutions of higher learning are under enormous pressure to balance the needs of the traditional education system with the trends of a modern society. Along with this challenge comes the task of keeping staff and faulty skilled in the latest technologies as well as keeping everyone informed of the latest offerings that the institution has for the students. In addition, is the issue of finding and retaining talented faculty and IT staff who are faithful keepers of the knowledge of technologies such as Fortran and COBOL but also those whom are keeping abreast of the latest developments in cloud computing and AI. But just how can someone else know who in which department is versed in what? Which staff member from admissions has been trained in all the degree possibilities of a particular school to bring along on recruiting events? Which faculty member has attended cloud computing training in a professional setting? The purpose of this paper is to explore the current ways that digital badging is being used to track the professional development of faculty and staff and to explore other ways to use the badges in the future to promote better communication, learning and growth opportunities for faculty and staff.

\section{LITERATURE REVIEW}

\section{Digital Badging}

Micro-credentialing, or digital badging is a form of identifying accomplishments that has been used for students and professionals alike. We are familiar with merit badges issued by scouts as they represent key accomplishments as they progress through different levels of requirements while progressing towards higher ranks.

Badges are a symbolic representation that the holder has completed some kind of academic training, they have some particular skill or have achieved some level of know-how about a particular product or service and can be seen commonly on sites like Linked-In, Mozilla, Facebook and Twitter (Dyjur \& Lindstrom, 2017). Badges are a good way to earn and display additional skill sets and competencies that are applicable to a specific discipline. As described by Casilli and Knight (2012), "Badges can provide a way to translate all types of learning into a powerful tool for getting jobs, finding communities of practice, demonstrating skills, and seeking out further learning" (Casilli \& 
Knight, 2012, p. 280). "Employers are looking for graduates with definitive skills, and a bachelor's degree may not sufficiently communicate what skills prospective employees have" (Ford, et al., 2015, p.32). Digital Badges and Micro-credentialing play a key role in displaying specific marketable skill sets to employers. Badges can show what skills are learned, who is the assessing authority, what criteria must be met to earn a badge and proof of the accomplishment. A challenge to verifying the particular skills that students may declare on a resume is that there is often to way to substantiate the claim. With digital badges and the metadata contained within however, claims are easily converted to verifiable evidence of skills obtained (Davies, Randall, \& West, 2015)

In another paper, Casilli and Hickey (2016) state that Digital Badges are designed to motivate more schools to move away from simple assessment scores and move towards actual student-generated results and exchanges. "Nonetheless, there is still little in academic degrees themselves that can be used to judge the quality of the learning or of the preparation level. By contrast, Open Badges can carry with them personalized evidence of achievement, thereby revealing levels of experience, competency, and quality." Open badge holders are encouraged to share their badges throughout their networks, as they collect and display them from digital "backpacks" or repositories for earned open digital badges (Casilli and Hickey, 2016, pp.118-119). "Open badges help a person to associate with a similar group to gain status within the group by earning badges deemed of value to the group. A network profile page that displays badges also facilitates the discovery of people with shared interests and/or skills" (Gibson, et al., 2015).

In their article "Developing Open Badges; A Comprehensive Approach" (2015) authors Devedzic \& Jovanovic add that Badges permit individuals to create and maintain a portfolio of micro - credentials earned during their career. They may be used to complement their resume and to help contribute to an individual's reputation within their professional and educational circles, as well as, within various online communities. These "Open Badges" are displayed through "badge backpacks" or a collection of badges earned from different issuers. One of the most common is the "Mozilla Backpack," (Devedzic \& Jovanovic, 2015, p.614).

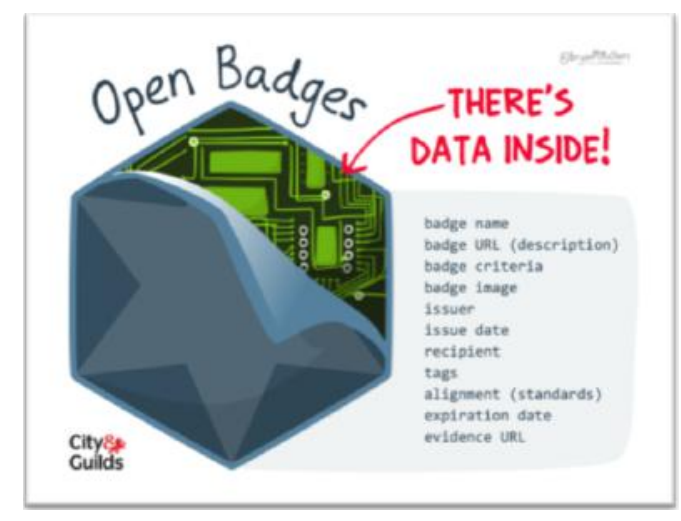

Figure 1. Example of an Open Badge (Bryan Mathers)

Unlike paper certificates that can be difficult to verify and keep track of, digital badges contain metadata that possess information about the awarding entity, issue data and expiration date (Fields, 2015). Figure 1 shows an example of what consists of an Open Badge. In their 2017 article, researchers Dyjur and Lindstrom discuss the potential uses of the digital badges in higher education and with findings as high as $87.5 \%$ of respondents agreeing or strongly agreeing that they were happy to receive a digital badge for an accomplishment, it seems that there is some potential traction to be gained by their expanded use. A limitation of this study, however, is that it seemed to be focused on the microcredentialing of faculty and graduate students and not the support staff of the universities at which it was conducted. The researchers also point out that few instructors have completed formal teaching programs and the use of microcredentials represents a way that faculty can represent skills trainings such as the completion of programs such as the Quality Matters program created by The Marland Online, Inc. The purpose of which is to help guarantee quality in online courses through faculty skills training and a standards framework (Robinson \& Wiser, 2016). 


\title{
Issues in Information Systems \\ Volume 20, Issue 4, pp. 21-26, 2019
}

Still, the relatively new concept of digital badging is approached with varying degrees if utility and efficacy. From using the badges to demonstrate a skill or an accomplishment or as a symbol of completing an entire college course, there is still discussion on how the badges can be meaningfully implemented (Carey \& Stefaniak, 2018). Researchers Gamrat, Zimmerman, Dudek, \& Peck in 2014, partnered with NASA and the National Science Teachers Association (NSTA) to design a case study around badging and decision making. The resulting system became known as the Teacher Learning Journeys (TJL) and is intended to enhance teacher productivity and fulfillment through the guidance of badge design and use in in the workplace (Carey \& Stefaniak, 2018).

\begin{abstract}
Alignment with Award Programs
One way that institutions are working to make an impact on how they are performing is to align their performance with quality and scorecard programs such as the Malcolm Baldridge Award. Balanced scorecard (BSC) programs such as the Malcolm Baldridge Award provide a methodology for evaluating IT investments against a company's vision and objectives in four categories: financial, customer, internal business processes, and learning and growth. With respect to education, the Malcolm Baldridge Award has further measures that look at student outcomes as well as the school leadership and governance (Beard \& Humphrey, 2014). By providing these quality standards, organizations can influence higher education institutions to align with their quality standards by providing innovative ways to meet training needs required by industry. In addition, new learners (GenZ) who are tech savvy, and are bored by the traditional approach to learning, are pushing the envelope of traditional education. They are demanding a much more agile learning environment that aligns with their ways of gathering knowledge. As a result, higher education institutions must have the ability to be more agile and adaptive to the needs of the new learners and to industry technology trends. "The role of organizational factors supports the importance of having work processes, technology resources, and an innovative culture where micro-credentials can be developed and offered for job attainment," Jeantet, 2018). Digital badges are just another part of the digital landscape and environment for these digital natives. They have high expectations with availability of technologies and getting the most out of their academic experience. It is the responsibility of universities and colleges to be able to provide this experience in order to fully prepare graduates with industry ready skill sets.
\end{abstract}

\section{Current State of Digital Badging in Education}

Jeantet (2018) discusses the impact and importance of micro credentialing in higher education. Universities and colleges can be more innovative when they are able to provide their students with more than just traditional formal learning and coursework. They can update their platforms with current industry technologies so that students can be trained in programs that provide skills to meet the demand of industry. However, this will not take away from traditional training, degrees, grades and certifications, but will enhance the learning process and provide a better path to career preparation (Jeantet, 2018).

The Teaching Online Program (TOP) is a professional development program for faculty and graduate students at a higher education institution in Canada and is designed to give participants skills to be able to teach online courses. The program runs over four weeks and gives the participants experience with synchronous and asynchronous materials, various types of activities, and assignments all geared towards online execution. At the end of the program, where those completing the program were given paper certificates, digital badges are now issued via their website (badges.ucalgary.ca). Recipients receive an email with information regarding their badge and how it may be used and managed as well as how to add it to physical portfolios should the need arise (Lindstrom \& Dyjur, 2017).

In 2017, researchers Fanfarelli and McDaniel at the University of Central Florida explored the usage of digital badges in higher education and concluded that while there is some uptick in their proliferation, the badges still have a long road ahead of them before widespread accepted use is achieved. In one study, cited by the researchers, students remarked that while the badges assisted them to understand in which direction they needed to focus their attention in an English composition course, they felt that the badges were better suited for high school freshmen and not for college-level students. The researchers also point out that badging may be a covert way of assessing student academic performance for those students who suffer from test anxiety (Fanfarelli \& McDaniel, 2017).

Dartmouth College is taking a unique approach to the topic by issuing each student a digital ePortfolio upon enrollment for the purpose of aggregating academic work and as a showcase for digital badges. Within their ePortfolio, students can customize the look of their and choose what is displayed and even browse the portfolios of faculty members for ideas and inspiration or goals. The objective of the ePortfolios reaches beyond meeting social needs because they are 
flexible enough to be shared with potential employers and graduate school admissions committees to used as a source of accomplishments for the student (Kohoe \& Goudzwaard, 2015)

The skill development of the new generations of workers is paramount to every single person that uses the facilities at every institution. While students are being prepared for their eventual careers, nothing is quite the same as the skills obtained from on the job training. In her 2009 article, Carroll Graham describes programs that are in place for early career academics but little to no programs for new staff and suggests that staff are instead told to take responsibility for their own development. She suggests professional development portfolios as a framework for self-development and as a way to archive and organize the projects that early careerists have worked on for future showcasing. Projects to be included in the portfolio can include items that would be standard types of project for one's own line of work as well as "pet" projects or learning a new skill such as learning to code in R programming that the new staff member just wanted to learn to do (Graham, 2009). Using the skill portfolio framework as outlined by Graham and the ePortfolio framework pioneered at Dartmouth for students, early careerists, faculty and experienced staff alike, the portfolios and badges have the potential to grow and become a truly useful showcase of talent and experience.

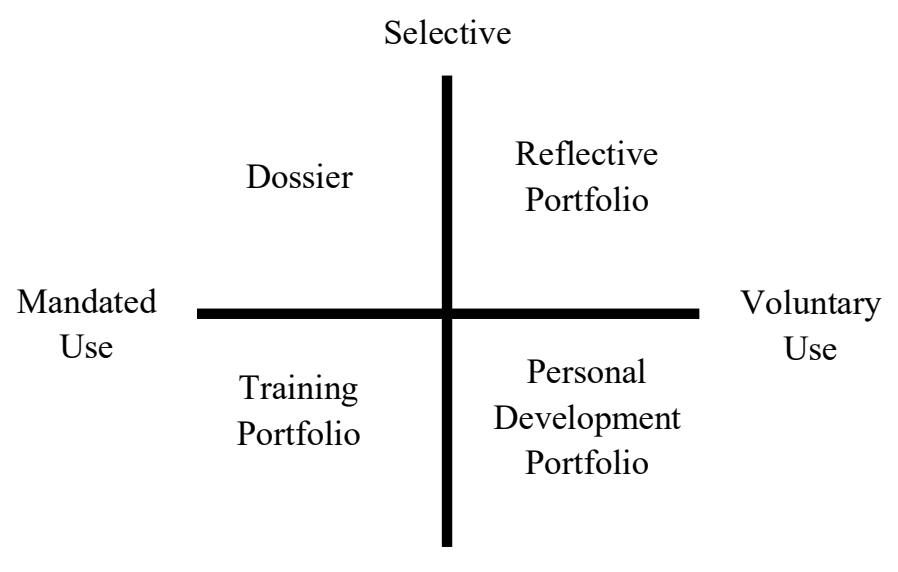

Developmental

Figure 2. Development portfolio framework (Graham, 2009).

The United Kingdom's popular Open University (OU) piloted a badged open course (BOC) in 2013 as a way to provide those participants in their massive online open courses (MOOCs) a way to demonstrate the skills they have achieved through the open courses. The BOCs are unsupported courses, meaning they have no tutors, last eight weeks, and are free to learners. As learners make their way through such courses as math 1 and 2, English, and digital literacy, they earn incremental badges that can be displayed on their OpenLearn Profile which can be kept private or shared publicly. Those learners who self-identified on the platform as teachers (15\%), 52\% of them said that the system had made a positive impact on their own teaching (Law, 2015).

\section{Blockchain and the Future of Digital Badges}

In 2011, Mozilla, with the help of a grant from the MacArthur Foundation, brought some order to the "wild west" of digital badges by developing an open badging platform as well as a backpack in which badge-earners could store their badges for sharing (Jirgensons \& Kapenieks, 2018). Since that time, Mozilla became the unofficial world standard for digital badges though other companies have started to issue them. The termination of the grant almost certainly spelled the doom for Mozilla's ability to continue the further development of their badging technology leaving many to wonder about the fate of the platform. Badges that were once issues would be left with no entity to verify their meta data or "zombie" badges would be left in the possession or earners with no place to digitally host them. Fortunately, in 2014, Mozilla launched the IMS Global Learning Consortium to help the continued growth and development of the technology. Since that time, a number of other entities have picked up right were Mozilla left off and have applied the latest technologies in an attempt to ensure growth and security to the badges. 
The phenomenon of blockchain is rearranging of existing technologies in a new way that brings about enhanced securities to databases by distributing datasets across multiple computers. The decentralized characteristics of the platform makes it harder to hack because any tampering of the data is more apparent to all nodes than is a centralized system. In 2015, Researchers at MIT's Media Lab created a digital wallet for storing digital certificates or badges, called Blockcerts (Jirgensons \& Kapenieks, 2018). The technology on which Blockcerts is based is a simplification of the Bitcoin cryptocurrency and has even been used to deliver student diplomas in addition to certificates. Once the user downloads the wallet, public and private keys are generated which the user can share with other institutions. The institution will then share back with the user their key which will unlock the information in the digital file which is delivered via email as a JSON file.

Since this incarnation of the technology is led by a university rather than a business, perhaps the longevity of the platform will be around for a longer period. With continued use and development, it is possible that we will see proliferation

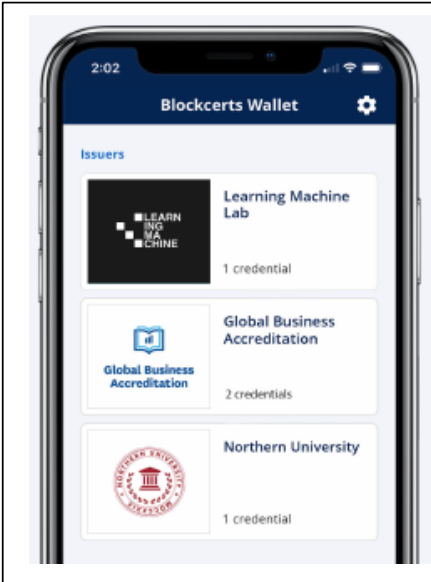

Figure 3. Blockcerts Wallet and continued use of the wallets and digital badges or certificates.

\section{FINDINGS}

A review of the literature reveals that digital badges, while there is some use of digital badges, they have been used sparingly at best throughout higher education and primarily only as symbols of student achievement. While the badges do have some use in the professional spheres, their usage seems limited to display on sites such as LinkedIn and Facebook only and do not appear to be widely shared as a way of signaling achievement. Since the end of the MacArthur Foundation grant that supported the initial development of the badges at Mozilla, which has now given way to the open-source badge platforms, little movement has been made in terms of bring mass-market success to the proliferation of digital badging. Researchers at MIT have likely made the most process by using the badges in their Blockcerts wallet as a way for students and others to store and share their badges and digital certificates, but it is unlikely that the wallet is gaining traction outside of the confines of the institution. In general, digital badges are starting to gain interest in higher education. However, as in many organizations, it is difficult to change the culture beyond traditional ways of doing things. As previously mentioned, there are pockets of innovative colleges and universities working to bring innovation into their environments through the use of digital badges and micro credentials. These first adopters will pave the way for other innovations. While new technologies such as Blockchain are being used, it seems that there is still a lot of work to be done in this area, as adoption still seems sluggish.

\section{DISCUSSION, CONCLUSION AND FUTURE RESEARCH}

This research uncovers new challenges about the technology needs of an institution in order to provide sufficient training in addition to traditional delivery of a degree. It also provides additional attention to a need for agile adoption in adjusting to the technology needs of future learners. As a result, there is a need for further research to understand and determine how prepared institutions are for the upcoming technology needs of future learners.

\section{REFERENCES}

Beard, D. F., \& Humphrey, R. L. (2014). Alignment of university information technology resources with the Malcolm Baldrige results criteria for performance excellence in education: a balanced scorecard approach. Journal of Education for Business, 89(7), 382-388. https://doi.org/10.1080/08832323.2014.916649

Carey, K. L., \& Stefaniak, J. E. (2018). An exploration of the utility of digital badging in higher education settings. Educational Technology Research and Development, 66(5), 1211-1229. https://oi.org/10.1007/s11423018-9602-1 
Casilli, C., \& Hickey, D. (2016). Transcending conventional credentialing and assessment paradigms with information-rich digital badges. The Information Society, 32(2), 117-129.

Casilli, C \& Knight, E. (2012), "Mozilla open badges", in Oblinger, DG. (Ed.), Game Changers:Education and Information Technology, Educause, available at: http://net.educause.edu/ir/library/pdf/pub7203.pdf

Davies, R., Randall, D., \& West, R. E. (2015). Using open badges to certify practicing evaluators. American Journal of Evaluation, 36(2), 151-163. https://doi.org/10.1177/1098214014565505

Dyjur, P., \& Lindstrom, G. (2017). Perceptions and uses of digital badges for professional learning development in higher education. TechTrends, 61(4), 386-392. https://doi.org/10.1007/s11528-017-0168-2

Devedzic, V., \& Jovanovic, J. (2015). Developing open badges: A comprehensive approach. Educational Technology, Research and Development, 63(4), 603-620. doi: http://dx.doi.org.pitt.idm.oclc.org/10.1007/s11423-0159388-3

Fields, E. (2015). Making visible new learning: professional development with open digital badge pathways. Partnership: The Canadian Journal of Library and Information Practice and Research, 10(1). https://doi.org/10.21083/partnership.v10i1.3282

Ford, E., Izumi,B., Lottes, J, Richardson, D. (2015). Badge it!: A collaborative learning outcomes based approach to integrating information literacy badges within disciplinary curriculum. Reference Services Review, 43(1), 31-44. https://doi.org/10.1108/RSR-07-2014-0026

Gibson, D., Ostashewski, N., Flintoff, K., Grant, S., \& Knight, E. (2015). Digital badges in education. Education and Information Technologies, 20(2), 403-410. doi: 10.1007/s10639-013-9291-7

Graham, C. (2009). Investing in early career general staff. Journal of Higher Education Policy and Management, 31(2), 175-183. https://doi.org/10.1080/13600800902825868

Jeantet, A. (2018). Exploring the development of micro-credentials for preparation for job attainment: An innovation study (11016802). Available from ProQuest Dissertations \& Theses Global. (2174323707). Retrieved from http://pitt.idm.oclc.org/login?url=https://search.proquest.com/docview/2174323707?accountid=14709

Jirgensons, M., \& Kapenieks, J. (2018). Blockchain and the future of digital learning credential assessment and management. Journal of Teacher Education for Sustainability, 20(1), 145-156. https://doi.org/10.2478/jtes2018-0009

Kehoe, A., \& Goudzwaard, M. (2015). Eportfolios, badges, and the whole digital self: how evidence-based learning pedagogies and technologies can support integrative learning and identity development. Theory Into Practice, 54(4), 343-351. https://doi.org/10.1080/00405841.2015.1077628

Law, P. (2015). Digital badging at The Open University: Recognition for informal learning. Open Learning: The Journal of Open, Distance and e-Learning, 30(3), 221-234. https://doi.org/10.1080/02680513.2015.1104500

Lindstrom, G., \& Dyjur, P. (2017). From student to instructor: Reflections on receiving and issuing digital badges for educational development. Transformative Dialogues: Teaching \& Learning Journal, 9(3).

Robinson, D. E., \& Wizer, D. R. (2016). Universal Design for Learning and the Quality Matters Guidelines for the Design and Implementation of Online Learning Events. International Journal of Technology in Teaching \& Learning, 12(1). 